\title{
PELATIHAN KEWIRAUSAHAAN DAN MANAJEMEN RITEL BAGI ANGGOTA DAN KARYAWAN KOPERASI KARYAWAN RUMAH SAKIT ISLAM SURAKARTA UNTUK PROGRAM PENINGKATAN PEMBERDAYAAN ANGGOTA
}

\author{
Supriyono, I Gusti Putu Diva Awatara, Tri Widianto \\ Manajemen, STIE “ADI UNGGUL BHIRAWA” SURAKARTA
}

\begin{abstract}
Based on Law no. 25 Year 1992 About Cooperatives consider that cooperatives need to further build themselves and built into a strong and independent based on the principle of cooperatives so as to be able to act as a pillar of the national economy. Therefore, cooperatives are responsible in the guidance of its members to be independent in terms of economic empowerment of its members to develop entrepreneurship spirit so as to help improve the welfare of members, as the implementation of the program members need to do coaching and training in entrepreneurship so as to become independent entrepreneurs And character, one of the efforts undertaken is trading business through retail business that is managed professionally and has competitiveness. This devotion will be implemented in KOPKAR RSIS or Koperasi employee Islamic Hospital Surakarta Jl. A Yani Pabelan Kartasura Sukoharjo, trainees targeted a total of 30 participants from members and employees KOPKAR RSIS. This implementation is planned for 6 months. The expected expenditure of this event is expected after the training participants are expected to have an independent entrepreneurship spirit and be able to apply the knowledge and skills acquired to be able to have a professionally managed and programmed retail business and have competitiveness in similar business.
\end{abstract}

Keywords: Entrepreneurship, Retail Management, Cooperatives

\begin{abstract}
ABSTRAK
Dengan berlandaskan UU No. 25 Tahun 1992 Tentang Perkoperasian menimbang bahwa koperasi perlu lebih membangun dirinya dan dibangun menjadi kuat dan mandiri berdasarkan prinsip koperasi sehingga mampu berperan sebagai soko guru perekonomian Nasional. Oleh karena itu koperasi ikut bertanggung jawab dalam pembinaan terhadap anggotanya untuk bisa mandiri dalam hal pemberdayaan ekonomi anggotanya untuk mengembangkan jiwa berwirausaha sehingga mampu membantu meningkatkan kesejahteraan anggota, sebagai implementasi dari program tersebut anggota perlu di lakukan pembinaan dan pelatihan dalam berwirausaha sehingga mampu menjadi wirausahawan yang mandiri dan berkarakter, salah satu usaha yang dilakukan yaitu usaha perdagangan melalui bisnis ritel yang dikelola secara profesional dan memiliki daya saing. Pengabdian ini akan dilaksanakan di KOPKAR RSIS atau Koperasi karyawan Rumah Sakit Islam Surakarta Jl. A Yani Pabelan Kartasura Sukoharjo, peserta pelatihan ditargetkan sejumlah 30 peserta dari anggota dan karyawan KOPKAR RSIS. Pelaksanaan ini direncanakan selama 6 bulan. Luaran yang diharapkan dari pengadian ini diharapkan setelah mengikuti pelatihan peserta diharapkan memiliki jiwa berwirausaha yang mandiri dan mampu mengaplikasi ilmu dan ketrampilan yang diperoleh untuk bisa mempunyai usaha ritel yang dikelola secara profesional dan terprogram serta mempunyai daya saing di bisnis serupa.
\end{abstract}

Kata kunci : Kewirausahaan, Manajemen Ritel, Koperasi

\section{PENDAHULUAN}

Badan Usaha Koperasi merupakan salah satu soko guru perekonomian di Indonesia. Hal ini dapat dilihat dari bukti nyata bahwa sebagian besar koperasi di Indonesia tidak mengalami krisis global pada tahun 2008. Perkembangan jumlah koperasi dari tahun ke tahun semakin bertambah,perkembangan koperasi baru terlihat dari sisi jumlahnya saja, secara umum dalam hal 
pemberdayaan anggota hanya sedikit koperasi yang sudah melakukan program ini, hal ini tentu saja memerlukan strategi khusus untuk badan usaha koperasi dalam meningkatkan pemberdayaan anggota supaya tujuan utama dari koperasi tersebut kesejahteraan anggota dapat tercapai.

Koperasi sebagai soko guru perekonomian. Dilihat dari sudut pasal 33 UUD 1945, keikutsertaan anggota masyarakat dalam memiliki faktor-faktor produksi itulah antara lain yang menyebabkan dinyatakannya koperasi sebagai bangun perusahaan yang sesuai dengan system ekonomi kerakyatan. Sebagaimana diketahui, perbedaan koperasi dari perusahaan perseroan terletak pada diterapkannya prinsip keterbukaan bagi semua pihak yang mempunyai kepentingan dalam lapangan usaha yang dijalankan oleh koperasi untuk turut menjadi anggota koperasi. Dalam kaitan dengan peningkatan kesempatan kerja dan berusaha , maka pemenuhan terhadap hak pekerjaan secara langsung atau tidak langsung dipengaruhi salah satunya oleh kebijakan pengembangan koperasi, usaha mikro, kecil dan menengah disamping juga sektor riil dan perdagangan, pengembangan koperasi dan UMKM memiliki potensi besar dan strategis dalam rangka mengurangi kemiskinan, mengingat pertumbuhan dan aktifnya sektor riil yang dijalankan koperasi dan UMKM mampu memberikan nilai tambah bagi masyarakat, yaitu tersedianya lapangan kerja dan meningkatkan pendapatan. Hal ini menunjukkan bahwa koperasi dan UMKM dapat menjadi penyeimbang pemerataan dan penyerapan tenaga kerja. koperasi dan UMKM dapat diandalkan sebagai penggerak roda ekonomi masyarakat pedesaan, perkotaan bahkan di daerah tertinggal.

Salah satu usaha untuk mencapai tujuan koperasi yaitu melalui pemberdayaan anggota untuk mengembangkan jiwa wirausaha yang mandiri mempunyai daya saing serta mempunyai keunggulan untuk memenangkan persaingan, hal inilah yang ingin dilakukan oleh koperasi karyawan Rumah Sakit Islam Surakarta dalam meningkatkan kesejahteraan anggota melalui pelatihan kewirausahaan sebagai wujud pertanggung jawaban dan kegiatan program kerja yang bermanfaat bagi anggota dan karyawan terutama sebagai persiapan bagi karyawan Rumah Sakit Islam Surakarta / RSIS terutama bagi anggota yang akan menghadapi masa pensiun.

Koperasi karyawan Rumah sakit Islam Surakarta / KOPKAR RSIS yang terintegrasi dengan Rumah sakit Islam Surakarta yang bergerak dalam bidang pelayanan kesehatan bagi masyarakat mempunyai bidang usaha yang potensial dan strategis untuk mendukung pelayanan kebutuhan konsumen Rumah Sakit Islam Surakarta dalam memberikan pelayanan kesehatan yang paripurna kepada masyarakat, salah usaha yang dijalankan oleh koperasi tersebut yaitu usaha minimarket yang buka selama 24 jam, sehingga pihak manajemen koperasi bermaksud untuk membekali karyawan dan anggotanya kemampuan pengelolaan manajemen ritel yang profesional dan mempunyai keunggulan sehingga mampu bersaing dengan bisnis serupa. Dengan mempertimbangkan permasalahan diatas perlu diadakan kegiatan pelatihan kewirausahaan dan manajemen ritel bagi karyawan dan anggota sebagai program pemberdayaan anggota sebagai salah satu cara untuk peningkatan kesejahteraan bagi anggota koperasi Karyawan Rumah Sakit Islam Surakarta/KOPKAR RSIS.

\section{METODE DAN APLIKASI \\ Pemecahan Masalah}

Esensi kewirausahaan yaitu tanggapan yang positif terhadap peluang memperoleh keuntungan untuk diri sendiri dan pelayanan yang baik pada pelanggan dan masyarakat. Cara yang etis dan produktif diperlukan untuk mencapai tujuan serta sikap mental untuk 
merealisasikan tanggapan yang positif tersebut. Suatu bangsa yang memiliki kelompok wirausaha yang besar akan lebih mudah untuk maju dan lebih tahan terhadap gangguan krisis, dan dikarenakan soko guru perekonomian Indonesia adalah koperasi maka kebutuhan akan wirausaha koperasi menjadi penting antara lain :

1. Pembangunan koperasi diarahkan agar makin memiliki kemampuan menjadi badan usaha yang makin efisien dan menjadi gerakan ekonomi rakyat yang tangguh dan berakar pada masyarakat.

2. Pelaksanaan fungsi dan peranan koperasi ditingkatkan melalui upaya peningkatan kebersamaan dan manajemen yang lebih professional.

3. Pemberian kemampuan yang seluar-luasnya di segala sektor kegiatan ekonomi dan penciptaan iklim usaha yang mendukung dengan kemudahan memperoleh permodalan.

4. Kerjasama antar koperasi dan antara koperasi dengan usaha Negara dan usaha swasta sebagai mitra usaha dikembangkan secara lebih nyata.

Memasuki era globalisasi saat ini, peran pelaku ekonomi seperti wirausaha sangat diperlukan untuk mendukung pertumbuhan ekonomi yang mandiri, tangguh, dan berdaya saing tinggi. Tiga jenis wirausaha menurut irfan (2011), pada dasarnya hakekat kewirausahaan adalah perwujudan sikap, perilaku, kemampuan , serta semangat yang sangat mendasar untuk mendukung kehandalan, ketangguhan dan keunggulan wirausaha yang memiliki ciri-ciri sebagai berikut :

a. Wirausaha handal memiliki ciri-ciri sebagai berikut : (1) memiliki rasa percaya diri dan mandiri dalam mengembangkan usaha (2) mampu memanfaatkan peluang usaha yang ada semaksimal mungkin demi keuntungannya (3) mencitai kegiatan usahanya tidak hanya secara lugas dan tangguh tetapi juga luwes dalam melindunginya (4) mampu melakukan komunikasi yang baik

b. Wirausaha tangguh memiliki ciri-ciri sebagai berikut : (1) mampu berpikir dan bertindak stratejik,adaptif dan berisiko (2) menggunakan berbagai keunggulan untuk memuaskan pelanggan (3) mengenali dan mengendalikan kekuatan serta kelemahan usaha (4) selalu berusaha meningkatkan kemampuan dan ketangguhan usaha.

c. Wirausaha unggul memiliki ciri-ciri sebagai berikut : (1) berani mengambil resiko serta mampu memperhitungkannya (2) selalu mengantisipasi perubahan dan akomodatif terhadap lingkungan usaha (3) bertindak kreatif memanfaatkan peluang pasar dan meningkatkan produktivitas usaha (4) meningkatkan keunggulan dan citra usaha melalui inovasi diberbagai usaha.

Seorang calon wirausaha harus memiliki kiat-kiat yang harus dapat digunakan usahanya untuk menjadikan usahanya maju dan memiki keunggulan kompetitif yaitu :

1. Batasi individu yang dapat menyetujui dan memberikan masukan secara langsung terhadap apa yang akan dicapai oleh usaha.

2. Tentukan bisnis usaha yang akan di tekuni

3. Focus terhadap dua atau tiga sasaran operasional spesifik pada jangka waktu tertentu

4. Bekerja sesuai dengan rencana yang telah disusun

5. Berikan penghargaan kepada karyawan yang berprestasi

6. Pekerjakanlah orang-orang yang memiliki prestasi baik

7. Perluas perkuat metode usaha yang dapat meningkatkan laba usaha

8. Rencanakan,arahkan, dan awasi modal usaha

9. Pertahankan pandangan-pandangan yang obyektif 
10. Lakukan inovasi secara periodic dengan mengevaluasi kesesuaian usaha kita dengan lingkungan

Resiko kewirausahaan, ketika memulai suatu bisnis wirausahawan akan menghadapi berbagai resiko yang sangat besar antara lain :

1. Risiko bisnis seperti ketika terjadi peperangan, bencana alam maka usaha kita akan kurang laku bahkan bangkrut

2. Risiko finansial seperti ketika usaha kita tidak berjalan baik maka kita akan merugi.

3. Risiko keluarga dan sosial yang ditimbulkan sebagai dampak atas sempitnya waktu untuk keluarga dan social

\section{Realisasi Pemecahan Masalah}

\section{Pembinaan dan Pengawasan Meliputi :}

a.Pemberian pelatihan tentang bagaimana berwirausaha bisnis ritel yang di kelola secara profesional dan berdaya guna

b. Memberikan pelatihan tentang penentuan ide bisnis dan peluang bisnis dalam berwirausaha terutama bisnis ritel

c.Memberikan pelatihan bagaimana menerapkan tentang bauran pemasaran atau ritel mix yang meliputi place,product, price,people,promotion

d. Pemberian pelatihan tata cara pengurusan ijin usaha kepada dinas Perindustrian dan Perdagangan

e.Pelatihan dan pembinaan serta pengembangan usaha bagi anggota yang sudah mempunyai usaha

\section{Pola Pendampingan dan Pengawasan Meliputi :}

a. Memberikan pendampingan dan tata cara memperoleh permodalan usaha melalui program kredit usaha rakyat (KUR) BRI

b. Pemberian pelatihan tentang modal kerja dan financial control .

\section{Khalayak Sasaran}

Khalayak sasaran dalam bentuk pelatihan yang diikuti oleh 37 orang anggota dan karyawan Koperasi Karyawan Rumah Sakit Islam Surakarta.

\section{Metode Pelaksanaan Pengabdian}

Kegiatan pelaksanaan pengabdian ini dalam bentuk pelatihan dan pendampingan dalam berwirausaha dalam bisnis ritel modern yang dikelola secara profesional serta bagaimana cara memperoleh modal usaha terutama melalui program kredit usaha rakyat ( KUR), adapun pelaksanaan kegitaan PKM ini dilaksanakan pada tanggal 24 april 2017 di aula KOPKAR RSIS pukul 09.00wib - selesai, yang diikuti oleh 37 orang yang terdiri dari anggota dan karyawan Koperasi Karyawan Rumah Sakit Islam Surakarta di Desa Pabelan Kartasura Sukoharjo. Metode yang digunakan dari kegiatan pelatihan dan pendampingan ini yaitu :

1. Metode ceramah dan penyampain materi oleh tim Pengabdian kepada Masyarakat (PKM) STIE-AUB Surakarta menyampaikan materi kewirausahaan tentang bisnis ritel modern yang dikelola secara profesional dan cara memperoleh modal usaha melalui program kredit usaha rakyat ( KUR ) 
2. Diskusi dan Tanya jawab, tim Pengabdian Masyarakat (PKM) STIE-AUB Surakarta memberikan kesempatan kepada peserta pelatihan untuk bertanya mengenai hal-hal belum jelas mengenai materi yang disampaikan

3. Konsultasi berkelanjutan kepada tim Pengabdian Kepada Mayarakat (PKM) STIE-AUB Surakarta jika masih diperlukan.

Persoalan umum yang dihadapi adalah bagaimana mempersiapkan masa pensiun karyawan Rumah Sakit Islam Surakarta agar mempunyai ketrampilan berwirausaha guna meningkatkan taraf ekonomi keluarga, sehingga perlu adanya pendampingan berupa motivasi dan pelatihan berwirausaha yang di kelola secara profesional dan mempunyai keunggulan kompetitif dan mempunyai daya saing yang kuat di bisnis serupa.

\section{HASIL DAN PEMBAHASAN}

Hasil dari kegiatan pengabdian masyarakat ini yaitu pelatihan dan pendampingan tentang berwirausaha yang dikelola secara profesional dan bagaimana memperoleh permodalan dari program kredit usaha rakyat ( KUR ) yang di ikuti oleh anggota dan karyawan koperasi Rumah Sakit Islam Surakarta pada tanggal 24 april 2017 sebanyak 37 peserta. Adapun hasil dari pelatihan ini adalah para peserta pelatihan memperoleh bekal dan keilmuan tentang pengelolaan suatu usaha bisnis yang di kelola secara profesional dan sehat secara financial dengan menggunakan metode Ritel Mix atau bauran pemasaran yang representatif dan berkesinambungan untuk mempertahankan usahanya ditengah persaingan usaha yang semakin ketat dalam menarik minat pelanggan terhadap produk yang kita miliki.

Beberapa peserta yang sudah memiliki usaha setelah mengikuti pelatihan ini adalah sebagai berikut :

1. Ibu Slamet Suprapti “Usaha Krupuk Kulit Rambak “ Desa Bendan Banyudono, Boyolali dengan daerah market boyolali, Surakarta, klaten dan sukoharjo

2. Bapak Salamun,SE “ Ayam Goreng Kremes DAFFA “ mendungan pabelan kartasura dengan daerah market Kampus UMS dan sekitarnya.

3. Ibu wiwiek Hartiwi " Salon Kecantikan UMI CANTIK “ Purbayan Baki Sukoharjo.

4. Bapak Suranto "Distributor GAS Elpiji “ Kertonatan Wirogunan kartasura.

5. Ibu Endah" Konveksi dan Reseller Sprei dan Sarung Bantal "gonilan Pabelan Kartasura.

Selain itu peserta pelatihan memperoleh pengetahuan tentang bagaimana memperoleh permodalan melalui program Kredit Usaha Rakyat (KUR ) dari BRI SYARIAH cabang Gemblegan Surakarta, dimana peserta pelatihan memperoleh pengetahuan dan informasi bagaimana syarat memperoleh modal usaha melalui program tersebut.

\section{KESIMPULAN DAN SARAN}

Seorang wirausaha termasuk wirausaha koperasi (wirakop) adalah orang yang mempunyai kemampuan melihat dan menilai kesempatan-kesempatan bisnis. Seorang wirakop adalah orang yang mempunyai sikap mental positif yang berorientasi pada tindakan dan mempunyai motavasi tinggi dalam mengambil resiko pada saat mengejar tujuannya.

Orang-orang yang berkompeten dalam menjalankan kewirausahaan koperasi yaitu anggota, manajer, birokrat dan katalis. Fungsi kewirausahaan dari masing-masing orang yang berkompeten tersebut tujuannya adalah untuk meningkatkan kegiatan usaha koperasi sehingga bisa berkembang dan bersaing dengan organisasai usaha lainnya dan anggota juga bisa 
mendapatkan manfaat dengan menjadi anggota koperasi dengan memperoleh pelayanan atas kebutuhannya dan memperoleh bagian keuntungan dari koperasi berupa sisa hasil usaha (SHU).

Hakikat dari fungsi wirausaha koperasi adalah melihat dan menerapkan kemungkinankemungkinan baru di bidang ekonomi, fungsi ini disebut fungsi inovatif yang dapat dijabarkan dalam berbagai bidang kegiatan seperti ; mengenal manfaat dan mengevaluasi keuntungan dari kombinasi-kombinasi baru, pembiayaan, teknologi, perencanaan dan pembangunan tempat produksi, pendidikan untuk anggota dalam hal kegiatan ekonomi, negosiasi dengan pemerintah dan pemasok.

Untuk mewujudkan hal di atas ternyata tidak mudah, banyak kendala yang harus dihadapi oleh para wirakop tersebut, sehingga masing-masing dari fungsi kewirausahaan dari para wirakop tersebut terkadang tidak bisa berjalan seperti apa yang diharapkan semula.

Disarankan kepada manajemen koperasi untuk selalu meningkat peran serta anggota dalam mengikuti pelatihan-pelatihan kewirausahaan untuk menstimulasi anggotanya untuk memiliki jiwa wirausaha serta menambah keilmuan anggota dalam mengembangkan usahanya guna menghadapi persaingan usaha yang semakin ketat dengan menonjolkan keunggulan kompetitif sebagai syarat memenangkan persaingan usaha.

\section{DAFTAR PUSTAKA}

Aulia, Astri, Adisti Madella Elmanisa \& Myra P Gunawan, 2009. Pola Distribusi Spasial Minimarket Di Kota-Kota Kecil, Institut Teknologi Bandung. Jurnal Perencanaan Wilayah dan Kota, Vol. 20 No. 2 p.78-94.

Setyawarman, Adityo. 2009. Pola Sebaran dan Faktor- Faktor Yang Mempengaruhi Pemilihan Lokasi Retail Modern (Studi Kasus Kota Surakarta). Tesis Pasca Sarjana UNDIP, 21 November 2013

Sunanto, Sandra, 2012. Modern Retail Impact on Store Preference and Traditional Retailers in West Java, Asian Journal of Business Research, Vol. 2 No. 2 p. 7-23

Utomo, Tri Joko, 2011. Persaingan Bisnis Ritel: Tradisional VS Modern. Jurnal Fokus Ekonomi, Vol. 6 No. 1 p. 122-133 http://www.depkop.go.id.

Avin Fadilla Helmi dan Tista Bendaravita Megasari, disarikan dari Hisricah RD,2005, Entrepreneurship. Sixth edition New York MC Grow Hill

Hendar dan Kusnadi, 1999, Ekonomi Koperasi, FEUI, Jakarta.

Ninik, Widiyah,1988, Koperasi dan Perekonomian Indonesia.

Sitio dan Tamba,2002, Koperasi Teori dan Praktek, Erlangga, Jakarta.

Sukandiyo, Ign, 1996, Manajemen Koperasi, Erlangga, Semarang.

Undang-Undang Nomor 25 Tahun 1992 tentang Perkoperasian

Peraturan Pemerintah Nomor 4 Tahun 1994 tentang Akta Koperasi

Peraturan Pemerintah Nomor 17 Tahun 1994 tentang Pembubaran Koperasi

Peraturan Pemerintah Nomor 9 Tahun 1995 tentang Usaha Simpan Pinjam

Peraturan Pemerintah Nomor 33 Tahun 1998 tentang Modal Penyertaan Koperasi

Instruksi Presiden Nomor 18 Tahun 1998 tentang Pengembangan Koperasi

Keputusan Menteri Nomor 36 Tahun 1998 tentang Pengembangan Koperasi

Keputusan Menteri Nomor 35 Tahun 1998 tentang Juklak USP 